\author{
Apr/2019 \\ Working Paper 19-09 \\ rcea.org/RePEc/pdf/wp19-09.pdf
}

\title{
Positive Early Life Rainfall Shocks and Adult Mental Health
}

\author{
Mochamad Pasha \\ World Bank, Indonesia \\ Marc Rockmore \\ Clark University, USA \\ Chih Ming Tan \\ University of North Dakota, USA \\ RCEA
}

Copyright belongs to the author. Short sections of the text, not exceeding three paragraphs, can be used provided proper acknowledgement is given.

The Rimini Centre for Economic Analysis (RCEA) was established in March 2007. RCEA is a private, nonprofit organization dedicated to independent research in Applied and Theoretical Economics and related fields. RCEA organizes seminars and workshops, sponsors a general interest journal, the Review of Economic Analysis (REA), and organizes a biennial conference, the Rimini Conference in Economics and Finance (RCEF). Scientific work contributed by the RCEA Scholars is published in the RCEA Working Paper series.

The views expressed in this paper are those of the authors. No responsibility for them should be attributed to the Rimini Centre for Economic Analysis. 
Positive Early Life Rainfall Shocks and Adult Mental Health ${ }^{1}$

\author{
Mochamad Pasha* \\ Marc Rockmore ${ }^{\#}$ \\ Chih Ming Tan
}

\begin{abstract}
We study the effect of early life exposure to above average levels of rainfall on adult mental health. While we find no effect from pre-natal exposure, post-natal positive rainfall shocks decrease average Center for Epidemiological Studies Depression (CESD) mental health scores by 15 percent and increase the likelihood of depression by 5 percent, a more than 20 percent increase relative to the mean. These effects are limited to females. We rule out prenatal stress and income shocks as pathways and find evidence suggestive of increased exposure to disease.
\end{abstract}

Keywords: Fetal origins, early life shocks, rainfall, mental health, climate change, Indonesia

JEL Classification Codes: I15; O12

\footnotetext{
${ }^{1}$ Tan thanks the Greg and Cindy Page Faculty Distribution Fund for financial support.

* Consultant, World Bank, Indonesia. Corresponding Author: mpp1287@ gmail.com

\# Department of Economics, Clark University, 950 Main Street, Worcester, MA 01610

${ }^{\wedge}$ Department of Economics, University of North Dakota, 293 Centennial Drive Stop 8369, Grand Forks, ND 58202
} 


\section{Introduction}

The effects of weather shocks have been widely studied, particularly in the development literature. A large strand of this literature examines how early life exposure to such shocks negatively affects later life outcomes ranging from physical health (Alderman et al. 2006; Barker 1995; Currie and Rossin-Slater 2013; Victora et al. 2006) to cognitive performance (Stein et al. 1972) to personality traits (Krutikova and Lilleor 2015). More recently, early life exposure to natural disasters and other weather shocks has been casually linked to a new outcome: adult mental health (Adhvaryu et al. 2017b; Dinkelman 2017; Liu et al. 2017; Maclean et al 2016). ${ }^{2}$

While relatively infrequently studied in economics, the costs associated with mental health disorders are particularly large, reaching up to 13 percent of the global disease burden, and are disproportionately concentrated in developing countries (Collins et al. 2011). Moreover, since these disorders are infrequently diagnosed or treated in developing countries, they represent an important and continuing 'invisible' burden (Demyttenaere et al., 2004) in these countries. For instance, in the context that we study, Indonesia, neuropsychiatric disorders account for roughly 10 percent of the disease burden (WHO 2011). Between 2012 and 2030, this burden is expected to lower Indonesia's aggregate output by US $\$ 0.98$ trillion hence presenting a significant headwind to overall growth and, potentially, to efforts to reduce poverty (Bloom et al. 2015).

The aggregate effects of weather on mental health are likely to increase over the coming years since climate change is expected to increase both the variability of weather and the frequency of 'extreme' events (Dell et al. 2014; Deschenes 2014). ${ }^{3}$ For instance, in Indonesia, while annual precipitation levels have slightly decreased in recent years, climate models suggest that climate change will increase precipitation in the coming decades (Case

\footnotetext{
${ }^{2}$ In part, this reflect a broader interest in the long run effects of early life stressors on adult mental health (Abel et al. 2014; Adhvaryu et al. 2017a; Almond and Mazumder 2011; Class et al. 2013; Dinkelman 2015; Persson and Rossin-Slater, forthcoming).

${ }^{3}$ A more developed literature focuses on heat. Although temperatures show considerable variation in certain regions, such as Africa (Adhvaryu et al. 2017b), this is not universally true, particularly in South and SouthEast Asia. For instance, in Jakarta, the capital of Indonesia, the monthly average air temperature between 1865 and 1995 was essentially bounded between 26 and 29 degrees centigrade (Harger 1995). In contrast, there is considerable variation in rainfall levels in Indonesia within and across years (Aldrian et al. 2003) Consequently, we choose to focus on rainfall.
} 
et al. 2007). These analyses point to heterogeneity in the local effects from climate change but the changes are likely to be substantial; for instance, parts of Sumatra are expected to experience between 10-30 percent more precipitation by 2080 .

In this paper, we examine the effects of early life exposure to above average levels of rainfall (i.e. positive rainfall shocks) on adult mental health. A robust literature examines the effects of early life exposure to rainfall shocks on human capital outcomes, both adolescent and adult. The early literature's focus on height has expanded to a variety of other outcomes in recent years including cognitive development (Shah and Steinberg, 2017; Leight et al. 2015), personality traits (Krutikova and Lilleor, 2015) and pro-social behavior (Ben Yishay, 2013). ${ }^{4}$ There is, however, only limited research on the effects of early life exposure to rainfall of adult mental health.

Maclean et al. (2016) include droughts and floods in their aggregate measure of exposure to natural disasters and find that early-life exposure to their aggregate measure resulted in worse adult mental health outcomes. Dinkelman (2017) focuses on negative weather shocks, specifically, droughts, and finds that prenatal exposure and, depending on the specification, exposure during the first year of life leads to higher adult rates of mental health disorder and disabilities. Liu et al. (2017) study typhoons (severe wind events associated with significant increases in precipitation) in Taiwan, and find a significant increase in mental illness in women. To the best of our knowledge, we are the first study to examine the effects of prenatal exposure to positive rainfall shocks on adult mental health, independent of other shocks.

By combining a national survey and a historical station-level panel of daily rainfall and temperature data, we create individual-specific measures of exposure to rainfall shocks during different early life growth periods: pre-natal, from ages 0 to 1 year, and from 1 to 2 years. Our measure of mental health employs the Center for Epidemiological Studies Depression (CESD) scale, a widely used diagnostic instrument for depression symptoms.

\footnotetext{
${ }^{4}$ While many studies focus examine developing countries, rainfall variation can also have important effects in developed country settings (Deschenes 2014; Deschenes and Greenstone 2011; and Deschenes et al 2009).
} 
We employ both the log of the raw CESD scores as well as the indicator for symptomatic depression using typical cutoff values employed by psychologists.

We find a clear and consistent negative relationship between post-natal positive rainfall exposure and our measures of mental health. In our benchmark specification, postnatal rainfall shocks decrease average mental health scores by 15 percent and increase the likelihood of depression by 5 percent, a more than 20 percent increase relative to the mean. These effects are robust to alternate specifications and measures of rainfall. Interestingly, these effects are limited to women in the sample.

We next examine particular pathways suggested by the literature on weather, climate change, and mental health (Berry et al. 2010) in conjunction with the broader literatures on early life shocks. While we are able to rule out pre-natal stress and income shocks from exposure to rainfall shocks as explanations for the increased depression observed, we do find evidence suggestive that changes in the disease environment may be a mechanism by which exposure to rainfall shocks affect mental health.

The remainder of the paper is organized as follows: sections 2 and 3 describe the methodology and data, respectively. Section 4 presents the main results and examines their robustness before investigating specific pathways. Finally, section 5 concludes.

\section{Specification}

To estimate the long-run effects of pre-natal and early life exposure of rainfall shocks on adult mental health, we follow Adhvaryu et al. (2017b) and estimate the following benchmark regression specification:

$$
\text { Mental Health } \text { icjdt }=\alpha+\beta \text { Rainfall }_{i h c g}+X_{i c g t}^{\prime} \theta+\gamma_{j d}+\rho_{c}+\tau_{t}+\varepsilon
$$

Where Mental Health $h_{i c j d t}$ is a measure of the mental health of person $i$ born in community $c$ in district $d$ during survey year $t$ in birth year $j$. Following the literature on early life shocks and its emphasis on the first 1,000 days of life as the "sensitive/critical period" for their effects (Barker 1995; Hoddinott 2010; Victora et al 2008), we use separate measures of exposure, Rainfall, for three growth periods, $g$; specifically, pre-natal, and between ages 0 and 1 year, and 1 and 2 years, respectively. While we initially only examine the effects 
of shocks before the age of 2 , we subsequently allow for the possibility of a later life effect and expand the measures of yearly exposure to age 7. $\beta$ is our coefficient of interest and represents the treatment effect of early life rainfall exposure on adult mental health.

$X_{\text {icgt }}^{\prime}$ is a vector of controls for survey year $t$ including the age of the respondent and of his/her mother, an indicator for a female head of household, highest education of the respondent's parents, household size, and the total number of health facilities in the community. To account for the effects of temperature described in Adhvaryu et al. (2017b), the vector also contains a measure of the average temperature during each growth period. $\gamma_{j d}$ is a vector of district-birth year fixed effects and therefore controls for any unobserved determinants of mental health which affect all individuals in a birth cohort within a given district. Consequently, we are identifying the effects of rainfall variation based solely on the within period variation of individuals born in the same district.

$\rho_{c}$ is a vector of fixed effects for the birth (and current) community of the respondent and therefore account for unobserved community characteristics which might affect mental health. Lastly, $\tau_{t}$ is a vector of fixed effects for the year of survey and controls for any unobserved factors which affect Indonesia at the time of the survey, $t$. Following the recommendations of Dell et al. (2014), we use robust standard errors clustered by subdistrict and birth year.

After establishing the effect of rainfall shocks, we next examine potential pathways. As we subsequently discuss, much of this analysis relies on variations of equation (1). One exception, however, is our discussion of disease epidemics which estimates the following equation:

$$
\text { DiseaseOutbreak }_{\text {crt }}=\alpha+\beta \text { Rainfall }_{\text {crt }}+\theta \text { Temp }_{\text {crt }}+\delta_{r}+\tau_{t}+\varepsilon
$$

where DiseaseOutbreak is binary indicator for a particular disease outbreak in community $c$ in region $r$ at survey year $t$. Rainfall is an indicator for rainfall shock in community $c$ in region $r$ at survey year $t$. Temp is the average annual temperature in community $c$ in region $r$ at survey year $t . \delta_{r}$ is a province-specific fixed effects, and $\tau_{t}$ is the survey year fixed effects. 


\section{Data}

With the exception of the rainfall data, we use data from the Indonesian Family Life Survey (IFLS), a longitudinal survey representative of approximately 83 percent of the population. Due to the availability of a mental health module based on the CESD-10 (which we discuss in the next section), we focus on the two most recent rounds, 2007 and 2015 (IFLS 4 and 5 , respectively). We limit the sample to individuals who answer the module (15 and older). As we subsequently explain, individuals are matched to the rainfall from their communities. Since we only have spatial coordinates for the IFLS communities, we further limit the sample to individuals who reside in their community of birth. Our final sample consists of 3,073 individuals born between 1986 and 2000 who reside in their birth community. ${ }^{5}$

\subsection{Mental Health}

Mental health is measured using the CESD-10. The CESD was first developed by Radloff (1977) and was designed for inclusion in surveys. Since its introduction, it has been employed by hundreds of surveys in both clinical and non-clinical settings. The CESD has been extensively validated to be a good instrument for "identifying individuals at risk for clinical depression, with good sensitivity and specificity, and high internal consistency (Lewinsohn et al. 1997)" according to the American Psychological Association. ${ }^{6}$ Two versions of the CESD exist: a 20-question version, the more common CESD-20, and the 10-question version included in the IFLS, CESD-10. Despite its shorter length, the reliability and validity of the CESD-10 is not affected (Shrout and Yager, 1989).

We calculate the CESD score using Likert scores. This method, which gives weights of 0 , 1,2 , and 3 to the responses (i.e. rarely or none, some days, etc.), is best at detecting major depressive episodes among first-visit psychiatric patients (Furukawa et al., 1997). The 10 underlying questions and the associated scores are described in Appendix Table 1. The score for the CESD-10 ranges from 0 to 30 . Scores of 10 or greater are symptomatic of

\footnotetext{
5 The 1986 lower threshold arises from the fact that we calculate rainfall deviations from a 10 -year average and use rainfall data beginning from 1976.

${ }^{6}$ See also Steffick (2000) for an extensive discussion of the CES-D.
} 
depression. ${ }^{7}$ We therefore create a binary indicator for depression using this threshold. To examine changes in overall mental health, we also measure mental health using the log of the CESD-10 score. Close to a quarter of the sample has a score of 10 or greater (Appendix Table 1).

\subsection{Rainfall}

The weather data comes from Indonesia's Meteorological, Climatological, and Geophysical Agency (Badan Meteorologi, Klimatologi, dan Geofisika). ${ }^{8}$ This station-level data contains information on the daily precipitation rate (measured in centimeters) and daily temperature (measured in degree Celsius). While station-level data offer considerable advantages, one difficulty is that changes in weather stations across time and space often result in missing observations (Aufhammer, 2013). To minimize the number of missing data points, we focus on 160 weather stations across Indonesia starting from 1976 since these contain substantially fewer missing observations.

The data from weather stations are used to interpolate estimates for the IFLS communities. Using the spatial coordinates of the weather stations and the communities, each community is matched with the three closest weather stations. The data at the community level is the weighted average of the daily data from the three closest weather stations, weighted by the inverse distance of the communities to the weather stations (Chen and Liu, 2012). The result of this process are community-level daily precipitation and temperature data which we match with individuals based on their birthdates to calculate rainfall exposure during the different growth periods. The prenatal period is calculated by counting backwards 270 days prior to the birth date, while the dates for the 0-2 years age groups are calculated by counting forward 365 days for each year until 2 years old.

Despite only using more recent data with fewer missing values, there are still missing observations in the station-level data (and therefore in the community-level data). Since no method can completely address this, we use alternate measures. In our preferred specification, we use the average rainfall levels for the period. Insofar as the actual rainfall

\footnotetext{
${ }^{7}$ Andresen et al. (1994) and Boey (1999) have demonstrated that a threshold of 10 or more minimizes false positives with minimal loss to sensitivity.

${ }^{8}$ There data is available at http://dataonline.bmkg.go.id/home. Note the website interface is in Indonesian.
} 
levels are uncorrelated with pattern of missing data, this will provide an accurate measure of rainfall. As an alternate measure, we follow Maccini and Yang (2007) and use rainfall $\mathrm{z}$-scores for the (unimputed) cumulative rainfall.

These rainfall measures are then used to construct the standardized rainfall z-scores, which measures the standard deviations from a community-level 10 year-moving average from the date of birth of the specific individual. While the community-fixed effects account for long-run community averages, local patterns may change for a variety of reasons including climate change. Consequently, the z-scores account for any trends over time. Following the climate literature, we define a rainfall shocks as a z-score greater than 0.7 during a growth period (Aguilar Esteva 2012; Andalon et al. 2016).

As an additional robustness check, we adapt the instrumented variable approach employed in Maccini and Yang (2007). We use rainfall shocks constructed from rainfall data from the second, and third closest stations to instrument the rainfall shock from the first closest weather station, with the restriction that these weather stations were operational before 2000. Contrary to the previous two approaches, where rainfall shocks for each growth period are defined as when the rainfall $\mathrm{z}$-score is greater than 0.7 standard deviations from the 10-year locality mean, in the IV approach, we follow Maccini and Yang (2007) in using $\log$ deviations from the 10-year locality mean as the measure for the rainfall shocks.

\subsection{Other Covariates}

In addition to the fixed effects, the estimation specifications include measures for the average temperature during each growth period, the age of the respondent and his/her mother, an indicator for a female head of household, highest education of the respondent's parents ${ }^{9}$, household size, and total health facilities in the communities. With the exception of the temperature data, these are all drawn from the IFLS.

Table 1 presents summary statistics for the variables used in this paper. There is considerable variation in our measures of mental health. The sample average for CESD scores is a little over $5(\log 1.54)$, considerably below the threshold of 10 for depression.

\footnotetext{
${ }^{9}$ Due to the high number of missing observations for the education of parents, a category for missing observations is created.
} 
At the same time, however, close to a quarter of the sample (23.2 percent) have CESD scores above the threshold. Within localities, there is also substantial fluctuation in rainfall with roughly one quarter of the sample exposed to at least one rainfall shock (z-score>0.7) during the first 1,000 days of life. Since the percent of the population exposed to shocks during the different growth periods is in-between 21 and 22 percent, this implies that a fraction of the population was exposed to multiple rainfall shocks during their first 1,000 days of life.

\section{Results}

\subsection{Main Results}

We begin by examining the link between rainfall and mental health. In Table 2, columns (1) and (3), we estimate the effects of rainfall deviations (from the local moving 10-year average) on the log CESD and depression indicator, respectively. For both measures, the estimated coefficients are insignificant. We therefore refine the analysis by focusing on shocks (z-score $>0.7$ ) and by allowing the effects to differ for positive and negative shocks. This allows rainfall shocks, such as floods and droughts, to have different effects on say agricultural production and, ultimately, on income. Similarly, disease burdens, such as malaria, may be affected non-linearly by positive/negative rainfall shocks.

The estimated coefficients are reported in columns (2) and (4). The negative rainfall shocks are never significant which contrasts with Dinkelman (2017) who finds an effect of droughts on the incidence of adult mental disabilities. This may partially arise from differences in the effects of low rainfall in the particular settings. In South Africa, below average rainfalls may result in droughts while in Indonesia, droughts are relatively uncommon. Below average rainfall is therefore potentially less destructive or harmless. However, the results are consistent with the study by Liu et al. (2017) on the effects of typhoons (which also engender a positive rainfall shock). For average mental health, only the estimated coefficient for a positive shock during age 1 is significant and implies a 15 percent increase in CESD scores. Similarly, only the coefficient for above average exposure at age 2 is significant for depression. The magnitude, however, is relatively large 
and implies a 5.5 percent increased likelihood of being depressed, an increase of $23 \%$ relative to the sample average.

Since the negative rainfall shocks are statistically insignificant, we focus on positive rainfall shocks for the remainder of the analysis. Although the literature on early life shocks focuses on the first 1,000 days after birth, this literature typically does not examine mental health. Consequently, it is not clear that the effects of early life exposure to weather variation are similarly limited to the first 1,000 days. We therefore examine this in Table 3. Columns (1) and (3) re-estimate equation (1) using only positive shocks up to age 2 . The results are broadly similar to Table 2 although the effects of rainfall shocks on average mental health extend to age 2. Columns (2) and (4) extend the growth period until age 7 and includes exposure to (positive) rainfall shocks in each year. The results are largely unchanged as none of the newly added estimated coefficients are significant while the significance and magnitude of the estimated coefficient in columns (1) and (3) remain largely unaffected. This suggests that the effects are limited to this early life period.

\subsection{Robustness}

We next examine the robustness of these results. We begin by investigating the effects of seasonality. In particular, as with much of the literature, equation (1) identifies the effects of weather (i.e. rainfall) based on the monthly variation in exposure for children born in the same year in the same geographic area (i.e. district). Other factors, however, are also correlated with seasonality. For instance, seasonality may affect household livelihoods and therefore the ability of parents to be with children, or exposure to sunlight, etc. Consequently, one important concern is whether omitted variables which are correlated with seasonality are potentially underlying our effects. We address this in Table 4 by replacing the district-year fixed effects with a district-birth year-birth quarter fixed effect. As a result, we are identifying based on variation in rainfall exposure of children born in the same quarter in the same year and district. Columns (1) and (3) replicate our estimates from Table 3 for shocks before age 2, while columns (2) and (4) replace the district-year fixed effects with a district-birthyear-birthquarter fixed effect. While the statistical significance decreases somewhat, the same pattern broadly emerges. The magnitude of the effects, however, are noticeably larger. Consequently, our results are not driven by 
seasonality and may perhaps somewhat underestimate the total effects of early-life exposure to rainfall variation.

In our earlier estimation exercises, z-scores were calculated based on the average rainfall in a community during a growth period. We replace these measures of shocks with an alternate measure of shocks based on z-scores for the cumulative rainfall during the growth periods. These use the same 0.7 standard deviation threshold as in earlier exercises. The results are presented in Table 5. Columns (1) and (3) replicate our benchmark results (reported in Table 3, columns (1) and (3)). The new estimates are presented in columns (2) and (4). As can be seen, the results are qualitatively and quantitatively similar.

Finally, we adapt the instrument variable approach employed in Maccini and Yang (2007). Rainfall shocks from the second and third closest weather stations are good instruments for rainfall shocks in the closest weather station (Appendix: Table 11: Panels A to G). However, the null hypothesis of the Durbin-Wu-Hausman test of exogeneity cannot be rejected in any first stage. Consequently, instrumental variables estimators are inefficient while the least squares estimates remain consistent and are therefore preferred.

\subsection{Heterogeneity}

We next examine heterogeneity along two dimensions: geographic and gender. While (positive) rainfall shocks, such as flooding, may affect urban areas, their effects may be stronger in rural areas for two reasons. First, rural households are relatively more vulnerable to weather fluctuations since they frequently depend on rain-fed agriculture with minimal irrigation. ${ }^{10}$ Second, poverty was primarily concentrated in rural areas during this period and poorer households are more affected by fluctuations in income (caused by the weather). We modify equation (1) to include interaction terms between the rainfall shocks in each growth period and a rural indicator. The results are presented in Table 6 . The effects of rainfall shocks on average mental health are present in both urban and rural areas. In urban areas, only the estimated coefficient for shocks at age 1 are significant. In rural area, both of the post-birth estimated coefficients are significant. In the specifications with

\footnotetext{
10 There is limited data for the percent of agricultural land in Indonesia that is irrigated. The World Development Indicators suggests that it varies between 11 and 16 percent.
} 
depression, the estimate coefficient for rainfall shocks at age 2 are significant at the 10 percent levels. Taken together, the results suggest that may rural areas drive the main results.

We next examine whether rainfall shocks affect boys and girls differently. Not only does the broader literature on early life shocks frequently find differences based on gender but Liu et al. (2017) find that the effect of typhoons on depression are limited to women. We modify equation (1) to include a binary variable for gender as well as interaction terms between the rainfall shocks in each growth period and a rural indicator. The estimated effects are presented in Table 7 and show that the main effects are completely driven by the effects on women; none of the estimated coefficients for men are significant. The estimated magnitudes are large: 12 to 28 percent higher average mental health scores and a 12 percent increased likelihood of being depressed, an increase of 50 percent relative to the sample mean. The estimated effect of early life shocks on the women's likelihood of being depressed matches Liu et al. (2017).

Unfortunately, the data do not allow us to understand the exact reasons for this. We are, however, able to rule out one channel discussed in the literature: the culling of weaker fetuses during pregnancy. For instance, Liu et al. (2017) note that their strong findings for women are consistent with weaker male fetuses being less likely to survive leading to stronger surviving males (Bozzoli et al. 2009; Liu et al. 2015; Bhalotra et al. 2010). Since there are no effects on exposure to prenatal shocks, this is unlikely to be the channel.

Based on the broader literature, one possible explanation is that girls are more vulnerable to shocks during these age groups. Another possibility is that the effects of these shocks lead to within household re-allocations of time and/or resources that disproportionately disadvantage girls. For instance, mothers may have to work outside of the house and spend less time with children (Miller and Urdinola. 2010) The size of the effects and unclear explanation makes this an important avenue for future research.

\subsection{Potential Pathways}

Having established a clear, causal relationship between early life exposure to rainfall shocks and adult mental health, we next examine the pathways suggested by the literature 
on weather, climate change and mental health (Berry et al. 2010) and the broader literatures on early life shocks. As we discuss below, we are able to rule out pre-natal stress and income shocks while we find evidence suggestive of the disease environment.

\subsubsection{Pre-Natal Stress}

As summarized in Adhvaryu et al. (2017b), pre-natal stress may affect prenatal growth and is linked with mental disorders and depression (Brown et al., 2000; O'Connor et al., 2005; St Clair et al., 2005; Watson et al., 1999). In addition to the direct effects on growth (Hansen 2009), there may be indirect effects via elevated activity in the mother's neuroendocrine system (the 'neurodevelopment hypothesis'; see, Bennet and Gunn 2006; Phillips 2007). With respect to weather, this background literature focuses primarily on temperature (as opposed to rainfall) (Hansen 2009). Within economics, Adhvaryu et al. (2017b) find consistent effects for temperature and Dinkelman (2017) and Liu et al. (2017) for rainfall (droughts and typhoons, respectively).

While we do not find any evidence for this in our main specification (Table 3: columns 1 and 3), we now examine alternate specifications to understand the role of prenatal shocks in our context. We first alter the specification to more closely match Adhvaryu et al. (2017b) who only control for prenatal shocks. However, the estimated coefficients remain insignificant (Table 8: columns 1 and 3). Another possibility is that only some of the trimesters matter but are insignificant when aggregated together. We therefore re-estimate our main estimation after disaggregating prenatal shocks by semester. The estimated coefficients for the trimesters are individually and jointly insignificant (Table 8: columns 2 and 4). Consequently, we are able to rule out pre-natal stress (and any other explanation which relies on prenatal shocks) as a possible underlying mechanism (at least, in the context of Indonesia).

\subsubsection{Income}

We next examine the effect of income shocks, a highly studied shock in the broader literature. Baird et al. (2013) find that positive income shocks for families improve the mental health of adolescent girls. Adhvaryu et al. (2017a) extend this to the long run effect on adult mental health by examining exogenous price variation in cocoa, the main cash 
crop in Ghana. The exact channels are unclear but may include nutrition or other food deprivation (Brown et al 2000; Neugubauer et al 1999; Pol et al. 2000; Susser and St Clair 2003)

Unfortunately, there is no corresponding cash crop in our data and there are no contemporaneous income or nutritional data. Consequently, we reply on a different income shock: the 1997 Asian Financial Crisis. The crisis was the worst economic shock in recent Indonesian history and had a devastating effect. Thomas and Frankenberg (2007) estimate that average per capita expenditure dropped by 25 percent between 1997 and 1998. At the same time, inflation in 1998 reached 80 percent. It took roughly until 2001 for the country to recover.

We replace the rainfall shock variables with variables for exposure to the Asian Financial Crisis during the different growth periods. The estimation results are presented in Table 9. None of the estimated coefficients are significant although many have the expected sign. If the primary pathway from rainfall shocks to adult mental health were through its effect on income, the largest economic event in recent years would presumably have a similar effect. However, this is not the case.

\subsubsection{Disease}

The disease environment has been linked to mental health through a variety of channels. For instance, pre-natal exposure through mothers to influenza has been linked to schizophrenia (Brown et al. 2004; Mednick et al 1988; Shi et al 2003). A recent review of major infectious diseases links them to neurocognitive and mental health outcomes (Chandy et al. 2015).

We focus here on two major diseases in Indonesia for which we have data: malaria and dengue. Cerebral malaria is associated with increased risk of subsequent mental health disorder in children (John et al. 2015). Among adults, malaria has been associated with concurrent mental disorders (Weiss 1985). More broadly, in utero and post-natal exposure to malaria are linked with lower adult education, income and poverty outcomes, which could be associated with adult mental health (Barreca 2010 Cutler et al 2010). Similarly, 
dengue has been associated with anxiety and depression, and mania in adults (Hashmi et al 2012; Jhanjee et al 2011; Lam 1996)

Unfortunately, the IFLS does not contain information on personal disease histories. Consequently, we examine how rainfall influences the disease environment using the PODES (Potensi Desa) data which contain information on disease outbreaks for all communities in Indonesia. We use data from the 2000, 2003, 2006, 2008, and 2011 survey rounds and merge the two data sets together to create a yearly-community level measure of disease outbreak for dengue fever and malaria. We estimate equation 2 in Table 10 and find that positive rainfall shocks increase the prevalence of both dengue and malaria, two diseases linked to depression (Barreca 2010; John et al. 2015; Weiss 1985). ${ }^{11}$ This is consistent with the WHO 2003 report on climate change and human health, where extreme weather events precipitate the transmission of tropical diseases such as malaria and dengue fever, especially in regions with high El Nino South Oscillation (ENSO) signal (McMichael, 2003). In the case of Indonesia, past ENSO events have been correlated with dengue epidemics (Gagnon et al, 2001). These results are consistent with disease outbreaks being a factor that can lead to decreased adult mental health.

\section{Conclusion}

This study examines the impact of early life exposure to positive rainfall shocks on adult mental health. We find a causal and robust effect: post-natal exposure leads to important decreases in average mental health and large increases in the rate of depression. Since positive rainfall shocks are relatively common in Indonesia (25\% of the sample experience a shock in the first 1,000 days post birth) and in the broader South East Asian region, this suggests a potentially large and understudied burden in the region arising from climate. Moreover, these effects are likely to be exacerbated by climate change in the coming years. While we are able to rule out prenatal and income shocks as pathways, important questions remain. With the data available to us, we were able to find support for the hypothesis that the mechanism that mediates early exposure to rainfall shocks on adult mental health may be through the influence of rainfall on disease prevalence. However, one important facet

\footnotetext{
${ }^{11}$ In results which we available upon request, we show that it is not linked with diarrhea, upper respiratory infection and measles epidemic outbreaks.
} 
of our analyses is to confirm the findings of Liu et al (2016) that these effects are present only in women. It is, however, unclear why this is the case. While the explanation may be biological, it may also reflect endogenous responses by households which can be addressed through policy. Likewise, our results are consistent with changes in the duration of breastfeeding (which has been linked to improved mental health outcomes in children (Oddy et al. 2010)). The median duration of exclusive breastfeeding in Indonesia is 0.7 months although some form of breastfeeding often continues into the second year of life (Statistics Indonesia et al., 2013). Our effects are limited to the first two years of life with the largest effects in the first year. It is possible that large weather shocks may affect the ability of women to nurse (e.g. stress, nutritional changes, time allocation) or that this is impacted by the prevalence of diseases. However, detailed data on breastfeeding is not available in the IFLS and so we were not able to investigate this potential channel. If confirmed, this would also open another policy avenue to address the changes in mental health brought about by early exposure to positive rainfall shocks. Finally, insofar as these effects are caused by the spread of diseases, our findings emphasize the importance of investments in basic public health and sanitation in developing countries. 


\section{References}

Adhvaryu, A., Fenske, J., Kala, N., Nyshadham, A., et al. (2016a). Fetal origins of mental health: Evidence from africa.

Adhvaryu, A., Fenske, J., and Nyshadham, A. (2016b). Early life circumstance and adult mental health.

Aguilar Esteva, A. (2012). Essays in Development and Labor Economics. Doctoral Dissertaion, Harvard University.

Alderman H, Hoddinott J, Kinsey B. (2006) Long Term Consequences of Early Childhood Malnutrition. Oxford Economic Paper, 58(3): 450-474.

Aldrian, E. and Dwi Susanto, R. (2003). Identification of Three Dominant Rainfall Regions within Indonesia and Their Relationship to Sea Surface Temperature. International Journal of Climatology, 23(12):1435-1452.

Almond, D. and Currie, J. (2011). Human Capital Development Before Age Five. In Handbook of Labor Economics, volume 4 Part B, chapter 15, pages 1315-1486. Elsevier.

Andalón, M., Azevedo, J. P., Rodríguez-Castelán, C., Sanfelice, V., and ValderramaGonzález, D. (2016). Weather Shocks and Health at Birth in Colombia. World Development, 82:69-82.

Andresen, E. M., Malmgren, J. A., Carter, W. B., and Patrick, D. L. (1994). Screening for Depression in Well Older Adults: Evaluation of. Prev Med, 10:77-84.

Auffhammer, M., Hsiang, S. M., Schlenker, W., and Sobel, A. (2013). Using weather Data and Climate Model Output in Economic Analyses of Climate Change. Review of Environmental Economics and Policy, page ret016.

Barreca, Alan I. 2010. The long-term economic impact of in utero and postnatal exposure to malaria. Journal of Human Resources, 45(4): 865-892.

Barker, D. J. (1995). Fetal Origins of Coronary Heart Disease. BMJ: British Medical Journal, 311(6998):171.

BenYishay, A. (2013). Childhood Shocks and Trust in Adulthood: Impacts of Early-life Rainfall in Sub-Saharan Africa. Technical Report, Working Paper, Department of Economics, University of New South Wales.

Bloom, D. E.; Chen, S.; McGovern, M.; Prettner, K.; Candeias, V.; Bernaert, A.; Cristin, S. (2015) Economics of Non-Communicable Diseases in Indonesia. In: World Economic Forum. 2015.

Boey, K. W. (1999). Cross-Validation of a Short Form of the CES-D in Chinese Elderly. International journal of geriatric psychiatry, 14(8):608-617. 
Brown, A. S., van Os, J., Driessens, C., Hoek, H. W., \& Susser, E. S. (2000). Further evidence of relation between prenatal famine and major affective disorder. American Journal of Psychiatry, 157(2), 190-195.

Cameron, A. C., Gelbach, J. B., and Miller, D. L. (2008). Bootstrap-Based Improvements for Inference with Clustered Errors. The Review of Economics and Statistics, 90(3):414-427.

Cameron, A. C. and Miller, D. L. (2015). A Practitioner's Guide to Cluster-Robust Inference. Journal of Human Resources, 50(2):317-372.

Case, M., Ardiansyah, F., and Spector, E. (2007). Climate Change in Indonesia: Implications for Humans and Nature. World Wildlife Federation

Chen, F.-W. and Liu, C.-W. (2012). Estimation of the Spatial Rainfall Distribution using Inverse Distance Weighting (IDW) in the Middle of Taiwan. Paddy and Water Environment, 10(3):209- 222.

Correia, S. (2016). Linear Models with High-Dimensional Fixed Effects: An Efficient and Feasible Estimator. Working Paper.

Cunha, F. and Heckman, J. J. (2008). Formulating, Identifying and Estimating the Technology of Cognitive and Noncognitive Skill Formation. The Journal of Human Resources, 43(4):738-782.

Currie, J. (2009). Healthy, Wealthy, and Wise: Is There a Causal Relationship between Child Health and Human Capital Development? Journal of Economic Literature, 47(1):87-122.

Currie, Janet, and Maya Rossin-Slater. 2013. "Weathering the Storm: Hurricanes and Birth Outcomes." Journal of Health Economics, 32, 487-503.

Collins, Pamela Y., Vikram Patel, Sarah S. Joestl, Dana March, Thomas R. Insel, and Abdallah S. Daar. 2011. "Grand Challenges In Global Mental Health.” Nature, 475(7354): 27-30

Dell, Melissa, Benjamin F. Jones, and Benjamin A. Olken. 2014. "What Do We Learn from the Weather? The New Climate-Economy Literature." Journal of Economic Literature, 52(3): 740-798.

Demyttenaere, K, et al. 2004. "Prevalence, Severity, And Unmet Need For Treatment Of Mental Disorders In The World Health Organization World Mental Health Surveys." Journal of the American Medical Association, 291(21): 2581-2590.

Deschenes, Olivier. 2014. "Temperature, Human Health, and Adaptation: A Review of the Empirical Literature.” Energy Economics, 46: 606-619. 
Deschênes, O. and Greenstone, M. (2011). Climate Change, Mortality, and Adaptation: Evidence from Annual Fluctuations in Weather in the US. American Economic Journal: Applied Economics, 3(4):152-185.

Deschênes, O., Greenstone, M., and Guryan, J. (2009). Climate Change and Birth Weight. The American Economic Review, 99(2):211-217.

Furukawa, T., Anraku, K., Hiroe, T., Takahashi, K., Kitamura, T., Hirai, T., Takahashi, K., and Iida, M. (1997). Screening for Depression Among First-Visit Psychiatric Patients: Comparison of Different Scoring Methods for the Center for Epidemiologic Studies Depression Scale using Receiver Operating Characteristic Analyses. Psychiatry and Clinical Neurosciences, 51(2):71-78.

Gagnon, A. S., Bush, A. B., and Smoyer-Tomic, K. E. (2001). Dengue Epidemics and the El Niño Southern Oscillation. Climate Research, 19(1):35-43.

Gluckman, P. and Hanson, M. (2006). Mismatch: Why Our World No Longer Fits Our Bodies. Oxford University Press.

Gluckman, P. D. and Hanson, M. A. (2005). The Fetal Matrix: Evolution, Development and Disease. Cambridge University Press.

Hashmi, A. M., Butt, Z., Idrees, Z., Niazi, M., Yousaf, Z., Haider, S. F., \& Bhatti, M. R. (2012). Anxiety and depression symptoms in patients with dengue fever and their correlation with symptom severity. The International Journal of Psychiatry in Medicine, 44(3), 199-210.

Hoddinott, J. (2010). Nutrition and Conditional Cash Transfer Program. In Adato, M. and Hoddinott, J., editors, Conditional Cash Transfers in Latin America. International Food Policy Research Institute.

Jhanjee, A., Bhatia, M. S., \& Srivastava, S. (2011). Mania in dengue fever. Industrial psychiatry journal, 20(1), 56.

John, C. C., Carabin, H., Montano, S. M., Bangirana, P., Zunt, J. R., and Peterson, P. K. (2015). Global Research Priorities for Infections that Affect the Nervous System. Nature, 527(7578):S178-S186.

Kishore, K., Subbiah, A., Sribimawati, T., Diharto, I. S., Alimoeso, S., Rogers, P., and Setiana, A. (2000). Indonesia Country Study. Asian Disaster Preparedness Center.

Krutikova, S. and Lilleør, H. (2015). Fetal Origins of Personality: Effects of Early Life Circumstances on Adult Personality Traits. Technical report.

Leight, J., Glewwe, P., \& Park, P. (2015). The Impact of Early Childhood Rainfall Shocks on the Evolution of Cognitive and Non-Cognitive Skills. Manuscript.

Liu, Elain M., Liu, Jin-Tan, and Tsen, Tsu-Yin Hazel. Fetal Origins of Mental Health: Evidence from Natural Disasters in Taiwan. Manuscript. 
Maccini, S. and Yang, D. (2009). Under the Weather: Health, Schooling, and Economic Consequences of Early-Life Rainfall. American Economic Review, 99(3):1006-26.

Manton, M., Della-Marta, P., Haylock, M., Hennessy, K., Nicholls, N., Chambers, L., Collins, D., Daw, G., Finet, A., Gunawan, D., et al. (2001). Trends in Extreme Daily Rainfall and Temperature in Southeast Asia and the South Pacific: 1961-1998. International Journal of Climatology, 21(3):269-284.

McMichael, A. J. (2003). Climate Change and Human Health: Risks and Responses. World Health Organization.

Mednick, S. A., Machon, R. A., Huttunen, M. O., \& Bonett, D. (1988). Adult schizophrenia following prenatal exposure to an influenza epidemic. Archives of general psychiatry, 45(2), 189-192.

Miller, G., and Urdinola, B.P. (2010) Cyclicality, Mortality, and the Value of Time: The Case of Coffee Price Fluctuations and Child Survival in Colombia. Journal of Political Economy, 118(1): 113-155.

Naylor, R. L., Battisti, D. S., Vimont, D. J., Falcon, W. P., and Burke, M. B. (2007). Assessing Risks of Climate Variability and Climate Change for Indonesian Rice Agriculture. Proceedings of the National Academy of Sciences, 104(19):7752-7757.

Neugebauer, R., Hoek, H. W., \& Susser, E. (1999). Prenatal exposure to wartime famine and development of antisocial personality disorder in early adulthood. Jama, 282(5), 455-462.

Oddy, W. H., Kendall, G. E., Li, J., Jacoby, P., Robinson, M., De Klerk, N. H., ... \& Stanley, F. J. (2010). The long-term effects of breastfeeding on child and adolescent mental health: a pregnancy cohort study followed for 14 years. The Journal of pediatrics, 156(4), 568-574.

Radloff, L. S. (1977). The CES-D Scale: A Self-Report Depression Scale for Research in the General Population. Applied psychological measurement, 1(3):385-401.

Shah, M., \& Steinberg, M.S.. (2017) Drought of Opportunities: Contemporaneous and Long-Term Impacts of Rainfall Shocks on Human Capital. Journal of Political Science, 125(2): 527-561.

Shi, L., Fatemi, S. H., Sidwell, R. W., \& Patterson, P. H. (2003). Maternal influenza infection causes marked behavioral and pharmacological changes in the offspring. Journal of Neuroscience, 23(1), 297-302.

Shrout, P. E. and Yager, T. J. (1989). Reliability and Validity of Screening Scales: Effect of Reducing Scale Length. Journal of clinical epidemiology, 42(1):69-78.

Statistics Indonesia (Badan Pusat Statistik-BPS), National Population and Family Planning Board (BKKBN), and Kementerian Kesehatan (Kemenkes-MOH), and 
ICF International. 2013. Indonesia Demographic and Health Survey 2012. Jakarta, Indonesia: BPS, BKKBN, Kemenkes, and ICF International.

Stein Z, Susser M, Saenger G, Marolla F. (1972) Nutrition and Mental Performance. Science, 179 (4062): 708-713.

Susser, E., \& Clair, D. S. (2013). Prenatal famine and adult mental illness: interpreting concordant and discordant results from the Dutch and Chinese Famines. Social science \& medicine, 97, 325-330.

Trewin, B., Baddour, O., and Kontongomde, H. (2007). The Role of Climatological Normals in a Changing Climate. World Meteorological Organization.

Thisyakorn, U., Thisyakorn, C., Limpitikul, W., \& Nisalak, A. (1999). Dengue infection with central nervous system manifestations. The Southeast Asian journal of tropical medicine and public health, 30(3), 504-506.

Victora, C. G., Adair, L., Fall, C., Hallal, P. C., Martorell, R., Richter, L., Sachdev, H. S., Maternal, Group, C. U. S., et al. (2008). Maternal and Child Undernutrition:

Consequences for Adult Health and Human Capital. The Lancet, 371(9609):340357.

Weiss, M. G. (1985). The Interrelationship of Tropical Disease and Mental Disorder: Conceptual Framework and Literature Review (Part I-Malaria). Culture, Medicine and Psychiatry, 9(2):121-200.

World Health Organization (2011). Mental Health Atlas 2011 - Indonesia, WHO.

World Meteorological Organization. (1989). Calculation of Monthly and Annual 30-year Standard Normals.

World Meteorological Organization. (2011). Guide to Climatological Practices. WMO, Geneva, Switzerland, 3rd edition. 


\section{Table 1: Summary Statistics}

\begin{tabular}{|c|c|c|c|c|}
\hline Variable & Mean & Std. Dev. & Variable & Percent \\
\hline Log CESD-10 Score & 1.74 & 0.75 & Depression & 23.16 \\
\hline Average Mean Temperature in Trimester 1 & 25.74 & 1.36 & In Utero Rain Above 0.7 SD & 21.61 \\
\hline Average Mean Temperature in Trimester 2 & 25.73 & 1.35 & Trimester 1 Rain Above 0.7 SD & 22.63 \\
\hline Average Mean Temperature in Trimester 3 & 25.72 & 1.38 & Trimester 2 Rain Above 0.7 SD & 22.06 \\
\hline Average Mean Temperature In Utero & 25.73 & 1.30 & Trimester Rain Above 0.7 SD & 22.20 \\
\hline Average Mean Temperature Age 1 & 25.73 & 1.31 & Age 1 Rain Above 0.7 SD & 21.22 \\
\hline Average Mean Temperature Age 2 & 25.77 & 1.32 & Age 2 Rain Above 0.7 SD & 21.98 \\
\hline Averege Mean Temperature First 1,000 Days & 25.74 & 1.28 & First 1,000 Days Rain Above 0.7 SD & 25.56 \\
\hline Age & 18.90 & 3.38 & Female Household Head & 16.27 \\
\hline Maternal Age & 26.76 & 6.42 & Maternal Education Level: & \\
\hline \multirow[t]{13}{*}{ Total Health Facilities in the Community } & 8.14 & 6.43 & Missing & 7.21 \\
\hline & & & No Schooling & 10.18 \\
\hline & & & Elementary School & 50.61 \\
\hline & & & Junior High School & 14.70 \\
\hline & & & High School & 13.30 \\
\hline & & & College and Above & 4.01 \\
\hline & & & Paternal Education Level: & \\
\hline & & & Missing & 26.82 \\
\hline & & & No Schooling & 4.15 \\
\hline & & & Elementary School & 38.25 \\
\hline & & & Junior High School & 11.00 \\
\hline & & & High School & 13.95 \\
\hline & & & College and Above & 5.83 \\
\hline Observations & 5,090 & & & \\
\hline
\end{tabular}


Table 2: Exposure to Early-Life Rainfall Shocks and Adult Mental Health

\begin{tabular}{|c|c|c|c|c|}
\hline & $(1)$ & $(2)$ & (3) & (4) \\
\hline & Log CESD-10 & Log CESD-10 & Depression & Depression \\
\hline \multirow[t]{2}{*}{ Rainfall Deviation Inutero } & -0.199 & & -0.002 & \\
\hline & $(0.124)$ & & $(0.070)$ & \\
\hline \multirow[t]{2}{*}{ Rainfall Deviation Age 1} & 0.137 & & -0.005 & \\
\hline & (0.194) & & $(0.170)$ & \\
\hline \multirow[t]{2}{*}{ Rainfall Deviation Age 2} & 0.147 & & 0.095 & \\
\hline & $(0.153)$ & & $(0.125)$ & \\
\hline \multirow[t]{2}{*}{ Inutero Rain Below 0.7 SD } & & 0.008 & & 0.001 \\
\hline & & $(0.047)$ & & $(0.028)$ \\
\hline \multirow[t]{2}{*}{ Age 1 Rain Below 0.7 SD } & & -0.039 & & -0.005 \\
\hline & & $(0.040)$ & & $(0.032)$ \\
\hline \multirow[t]{2}{*}{ Age 2 Rain Below 0.7 SD } & & -0.023 & & 0.011 \\
\hline & & $(0.040)$ & & $(0.017)$ \\
\hline \multirow[t]{2}{*}{ Inutero Rain Above 0.7 SD } & & -0.019 & & -0.003 \\
\hline & & $(0.060)$ & & $(0.035)$ \\
\hline \multirow[t]{2}{*}{ Age 1 Rain Above 0.7 SD } & & $0.153 * * *$ & & 0.020 \\
\hline & & $(0.046)$ & & $(0.031)$ \\
\hline \multirow[t]{2}{*}{ Age 2 Rain Above 0.7 SD } & & 0.063 & & $0.055^{*}$ \\
\hline & & $(0.036)$ & & $(0.029)$ \\
\hline Observations & 3631 & 3631 & 3631 & 3631 \\
\hline R-squared & 0.441 & 0.442 & 0.377 & 0.378 \\
\hline Survey Year FE & Yes & Yes & Yes & Yes \\
\hline District $x$ Birth Year FE & Yes & Yes & Yes & Yes \\
\hline Control Variables & Yes & Yes & Yes & Yes \\
\hline Community FE & Yes & Yes & Yes & Yes \\
\hline
\end{tabular}

Estimations use IFLS survey weights. Standard errors are clustered by sub-district and birth year. Control variables are average temperature in corresponding growth period, age when surveyed, female household head, maternal age, indicators for parents highest level of education, household size, and total health facilities in the communities. 
Table 3: Exposure to Postive Early-Life Rainfall Shocks and Adult Mental Health

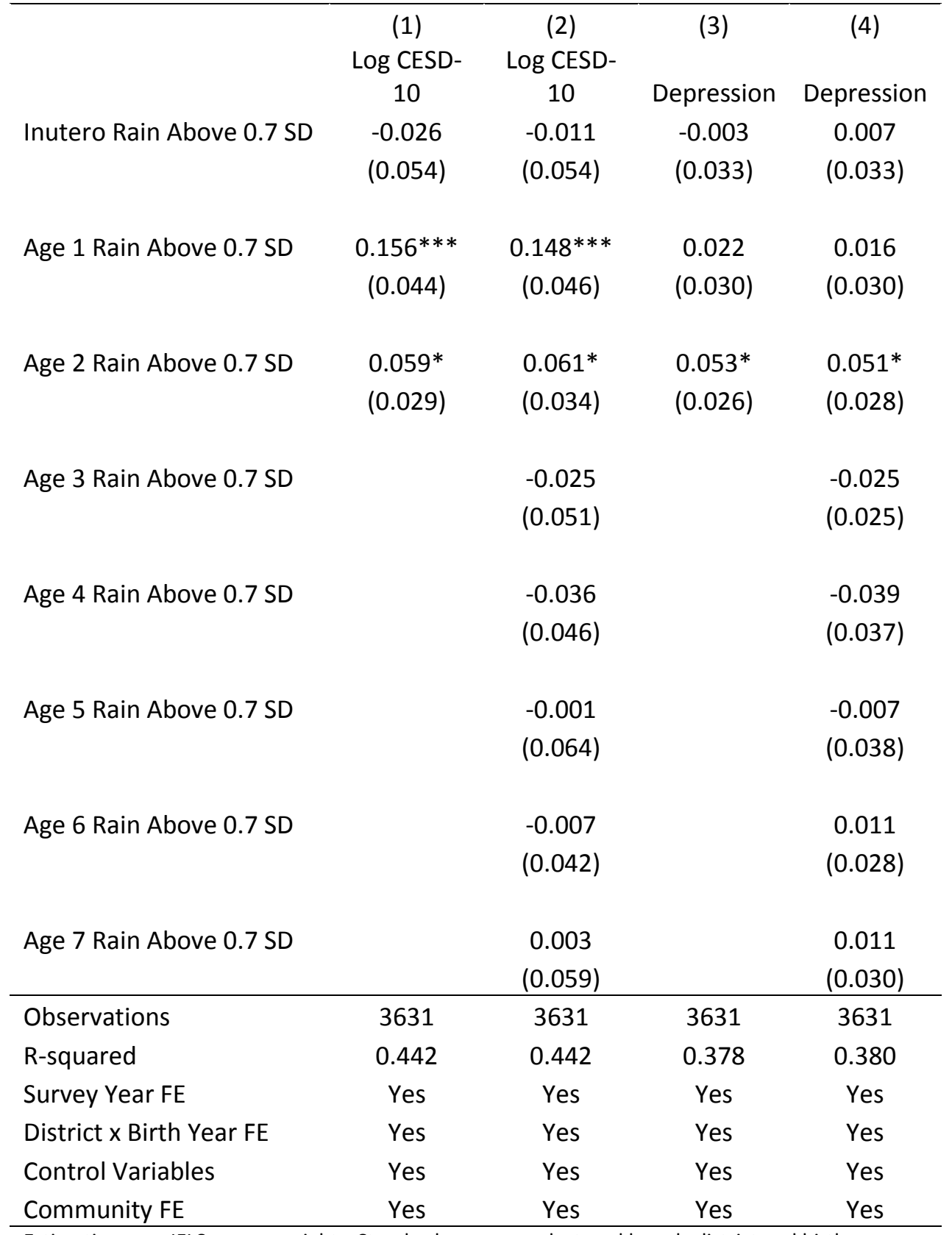

Estimations use IFLS survey weights. Standard errors are clustered by sub-district and birth year. Control variables are average temperature in corresponding growth period, age when surveyed, female household head, maternal age, indicators for parents highest level of education, household size, and total health facilities in the communities. 
Table 4: Exposure to Positive Early-Life Rainfall Shocks and Adult Mental Health (Birth Seasonality)

\begin{tabular}{|c|c|c|c|c|}
\hline & $\begin{array}{c}(1) \\
\text { Log CESD- } \\
10 \\
\end{array}$ & $\begin{array}{c}(2) \\
\text { Log CESD- } \\
10\end{array}$ & $\begin{array}{c}\text { (3) } \\
\text { Depression }\end{array}$ & $\begin{array}{c}\text { (4) } \\
\text { Depression }\end{array}$ \\
\hline Inutero Rain Above 0.7 SD & $\begin{array}{c}0.001 \\
(0.103)\end{array}$ & $\begin{array}{l}-0.012 \\
(0.102)\end{array}$ & $\begin{array}{c}0.018 \\
(0.044)\end{array}$ & $\begin{array}{c}0.011 \\
(0.047)\end{array}$ \\
\hline Age 1 Rain Above 0.7 SD & $\begin{array}{l}0.222^{*} \\
(0.108)\end{array}$ & $\begin{array}{l}0.206^{*} \\
(0.113)\end{array}$ & $\begin{array}{l}-0.007 \\
(0.045)\end{array}$ & $\begin{array}{l}-0.015 \\
(0.050)\end{array}$ \\
\hline Age 2 Rain Above 0.7 SD & $\begin{array}{l}0.164^{*} \\
(0.081)\end{array}$ & $\begin{array}{c}0.149 \\
(0.088)\end{array}$ & $\begin{array}{l}0.091^{*} \\
(0.046)\end{array}$ & $\begin{array}{l}0.075 \\
(0.051)\end{array}$ \\
\hline Age 3 Rain Above 0.7 SD & & $\begin{array}{l}-0.031 \\
(0.110)\end{array}$ & & $\begin{array}{l}-0.070 \\
(0.049)\end{array}$ \\
\hline Age 4 Rain Above 0.7 SD & & $\begin{array}{l}-0.079 \\
(0.074)\end{array}$ & & $\begin{array}{l}-0.092 \\
(0.066)\end{array}$ \\
\hline Age 5 Rain Above 0.7 SD & & $\begin{array}{l}0.017 \\
(0.129)\end{array}$ & & $\begin{array}{l}0.017 \\
(0.074)\end{array}$ \\
\hline Age 6 Rain Above 0.7 SD & & $\begin{array}{l}-0.066 \\
(0.106)\end{array}$ & & $\begin{array}{c}0.001 \\
(0.063)\end{array}$ \\
\hline Age 7 Rain Above 0.7 SD & & $\begin{array}{l}0.073 \\
(0.095)\end{array}$ & & $\begin{array}{l}-0.000 \\
(0.062)\end{array}$ \\
\hline $\begin{array}{l}\text { Observations } \\
\text { R-squared }\end{array}$ & $\begin{array}{l}2295 \\
0.569\end{array}$ & $\begin{array}{l}2295 \\
0.572\end{array}$ & $\begin{array}{l}2295 \\
0.515\end{array}$ & $\begin{array}{l}2295 \\
0.517\end{array}$ \\
\hline $\begin{array}{l}\text { Survey Year FE } \\
\text { District x Birth Year x Birth Quarter }\end{array}$ & Yes & Yes & Yes & Yes \\
\hline $\mathrm{FE}$ & Yes & Yes & Yes & Yes \\
\hline Control Variables & Yes & Yes & Yes & Yes \\
\hline Community FE & Yes & Yes & Yes & Yes \\
\hline
\end{tabular}

*** $\mathrm{p}<0.01,{ }^{* *} \mathrm{p}<0.05,{ }^{*} \mathrm{p}<0.1$

Estimations use IFLS survey weights. Standard errors are clustered by sub-district and birth year. Control variables are average temperature in corresponding growth period, age when surveyed, female household head, maternal age, indicators for parents highest level of education, household size, and total health facilities in the communities. 
Table 5: Robustness to Alternative Rainfall Measures

\begin{tabular}{lcccc}
\hline & $(1)$ & $(2)$ & $(3)$ & $(4)$ \\
In Utero Rain Above 0.7 SD & -0.026 & -0.028 & -0.003 & 0.003 \\
& $(0.054)$ & $(0.050)$ & $(0.033)$ & $(0.034)$ \\
& & & & \\
Age 1 Rain Above 0.7 SD & $0.156^{* * *}$ & $0.140^{* * *}$ & 0.022 & 0.019 \\
& $(0.044)$ & $(0.039)$ & $(0.030)$ & $(0.028)$ \\
Age 2 Rain Above 0.7 SD & & & & \\
& $0.059^{*}$ & $0.067^{* *}$ & $0.053^{*}$ & $0.061^{* *}$ \\
\hline Rainfall & $(0.029)$ & $(0.028)$ & $(0.026)$ & $(0.024)$ \\
\hline Observations & Average & Cumulative & Average & Cumulative \\
R-squared & 3631 & 3642 & 3631 & 3642 \\
Survey Year FE & 0.442 & 0.441 & 0.378 & 0.376 \\
District x Birth Year FE & Yes & Yes & Yes & Yes \\
Control Variables & Yes & Yes & Yes & Yes \\
Community FE & Yes & Yes & Yes & Yes \\
\hline Estimations & Yes & Yes & Yes \\
\hline
\end{tabular}

Estimations use IFLS survey weights. Standard errors are clustered by sub-district and birth year. Control variables are average temperature in corresponding growth period, age when surveyed, female household head, maternal age, indicators for parents highest level of education, household size, and total health facilities in the communities. 
Table 6: Effects of Rainfall on Adult Mental Health, Rural vs Urban

\begin{tabular}{|c|c|c|}
\hline & $\begin{array}{c}(1) \\
\text { Log CESD- } \\
10\end{array}$ & $\begin{array}{c}\text { (4) } \\
\text { Depression }\end{array}$ \\
\hline Effect of In Utero Shock in Urban Communities & $\begin{array}{c}0.060 \\
(0.088)\end{array}$ & $\begin{array}{c}0.028 \\
(0.046)\end{array}$ \\
\hline Effect of Age 1 Shock in Urban Communities & $\begin{array}{l}0.133^{*} \\
(0.075)\end{array}$ & $\begin{array}{c}0.046 \\
(0.053)\end{array}$ \\
\hline Effect of Age 2 Shock in Urban Communities & $\begin{array}{l}-0.002 \\
(0.055)\end{array}$ & $\begin{array}{c}0.044 \\
(0.038)\end{array}$ \\
\hline Effect of In Utero Shock in Rural Communities & $\begin{array}{l}-0.068 \\
(0.063)\end{array}$ & $\begin{array}{l}-0.018 \\
(0.037)\end{array}$ \\
\hline Effect of Age 1 Shock in Rural Communities & $\begin{array}{c}0.165 * * \\
(0.069)\end{array}$ & $\begin{array}{c}0.010 \\
(0.032)\end{array}$ \\
\hline Effect of Age 2 Shock in Rural Communities & $\begin{array}{c}0.097 * * \\
(0.039)\end{array}$ & $\begin{array}{l}0.059 * \\
(0.034)\end{array}$ \\
\hline Observations & 3631 & 3631 \\
\hline R-squared & 0.443 & 0.378 \\
\hline Survey Year FE & Yes & Yes \\
\hline District $\times$ Birth Year FE & Yes & Yes \\
\hline Control Variables & Yes & Yes \\
\hline Community FE & Yes & Yes \\
\hline \multicolumn{3}{|c|}{$\begin{array}{l}\text { Estimations use IFLS survey weights. Standard errors are clustered by sub- } \\
\text { district and birth year. Control variables are average temperature in } \\
\text { corresponding growth period, age when surveyed, female household head, } \\
\text { maternal age, indicators for parents highest level of education, household } \\
\text { size, and total health facilities in the communities. }\end{array}$} \\
\hline
\end{tabular}


Table 7: Effects of Rainfall on Adult Mental Health, Male vs Female

(1)

(4)

Effect of In Utero Shock for Men

$\begin{array}{cc}\text { Log CESD-10 } & \text { Depression } \\ -0.031 & -0.002 \\ (0.056) & (0.038)\end{array}$

Effect of Age 1 Shock for Men

$0.096 \quad 0.028$

(0.060)

(0.037)

Effect of Age 2 Shock for Men

$\begin{array}{cc}0.035 & 0.020 \\ (0.021) & (0.028)\end{array}$

Effect of In Utero Shock for Women

0.027

0.019

(0.084)

Effect of Age 1 Shock for Women

$\begin{array}{cc}0.276 * * * & 0.039 \\ (0.052) & (0.036)\end{array}$

Effect of Age 2 Shock for Women

$0.118 *$

$0.118 * *$

(0.063)

(0.043)

Observations
R-squared
Survey Year FE
District x Birth Year FE
Control Variables

3631

3631

Community FE

0.445

0.380

Yes Yes

Yes Yes

Estimations use IFLS survey weights. Standard errors are clustered by subdistrict and birth year. Control variables are gender, average temperature in corresponding growth period, age when surveyed, female household head, maternal age, indicators for parents highest level of education, household size, and total health facilities in the communities. 
Table 8: Re-Examining the Impact of In Utero Shocks

\begin{tabular}{|c|c|c|c|c|}
\hline & (1) & $(2)$ & (3) & (4) \\
\hline & $\begin{array}{c}\text { Log CESD- } \\
10\end{array}$ & $\begin{array}{c}\text { Log CESD- } \\
10\end{array}$ & Depression & Depression \\
\hline \multirow[t]{2}{*}{ Inutero Rain Above 0.7 SD } & -0.040 & & -0.008 & \\
\hline & $(0.053)$ & & $(0.025)$ & \\
\hline \multirow[t]{2}{*}{ Trimester 1 Rain Above 0.7 SD } & & 0.032 & & 0.011 \\
\hline & & (0.039) & & $(0.031)$ \\
\hline \multirow[t]{2}{*}{ Trimester 2 Rain Above 0.7 SD } & & 0.008 & & 0.001 \\
\hline & & $(0.042)$ & & $(0.024)$ \\
\hline \multirow[t]{2}{*}{ Trimester 3 Rain Above 0.7 SD } & & -0.020 & & -0.018 \\
\hline & & $(0.035)$ & & $(0.021)$ \\
\hline \multirow[t]{2}{*}{ Age 1 Rain Above $0.7 \mathrm{SD}$} & & $0.164 * * *$ & & 0.010 \\
\hline & & $(0.054)$ & & $(0.033)$ \\
\hline \multirow[t]{2}{*}{ Age 2 Rain Above 0.7 SD } & & $0.076^{*}$ & & $0.055^{* *}$ \\
\hline & & $(0.037)$ & & $(0.025)$ \\
\hline Observations & 3631 & 3631 & 3631 & 3631 \\
\hline R-squared & 0.403 & 0.407 & 0.378 & 0.337 \\
\hline Survey Year FE & Yes & Yes & Yes & Yes \\
\hline District $x$ Birth Year FE & Yes & Yes & Yes & Yes \\
\hline Control Variables & Yes & Yes & Yes & Yes \\
\hline Community FE & Yes & Yes & Yes & Yes \\
\hline
\end{tabular}

Estimations use IFLS survey weights. Standard errors are clustered by sub-district and birth year. Control variables are average temperature in corresponding growth period, age when surveyed, female household head, maternal age, indicators for parents highest level of education, household size, and total health facilities in the communities. 
Table 9: Exposure to the Economic Crisis and Adult Mental Health

\begin{tabular}{|c|c|c|}
\hline & (1) & (2) \\
\hline & Log CESD-10 & Depression \\
\hline \multirow[t]{2}{*}{ Exposed to Crisis Inutero } & 0.169 & -0.023 \\
\hline & $(0.184)$ & $(0.143)$ \\
\hline \multirow[t]{2}{*}{ Exposed to Crisis Age 1} & 0.085 & -0.007 \\
\hline & $(0.187)$ & $(0.143)$ \\
\hline \multirow[t]{2}{*}{ Exposed to Crisis Age 2} & -0.057 & 0.060 \\
\hline & $(0.185)$ & $(0.172)$ \\
\hline Observations & 5783 & 5783 \\
\hline R-squared & 0.372 & 0.328 \\
\hline Survey Year FE & Yes & Yes \\
\hline District $x$ Birth Year FE & Yes & Yes \\
\hline Control Variables & Yes & Yes \\
\hline Community FE & Yes & Yes \\
\hline \multicolumn{3}{|c|}{$\begin{array}{l}\text { Individuals are defined as exposed to the Indonesian } \\
\text { economic crisis if the dates of their respective growth } \\
\text { period coincides with the crisis. The period of the } \\
\text { Indonesian economic crisis is between December } 1997 \\
\text { and December } 2001 \text { (Strauss et.al., 2004; Laeven and } \\
\text { Valencia, 2011). Estimations use IFLS survey weights. } \\
\text { Standard errors are clustered at the community level. All } \\
\text { estimations controlled for age when surveyed, female } \\
\text { household head, maternal age, indicators for parents } \\
\text { highest level of education, household size, and total } \\
\text { health facilities in the communities. }\end{array}$} \\
\hline
\end{tabular}


Table 10: Rainfall Shocks and Community Epidemics

\begin{tabular}{|c|c|c|}
\hline \multirow{4}{*}{ Yearly Rain Above 0.7 SD } & (1) & (2) \\
\hline & $\begin{array}{c}\text { Dengue Fever } \\
\text { Epidemic }\end{array}$ & $\begin{array}{l}\text { Malaria } \\
\text { Epidemic }\end{array}$ \\
\hline & $0.062 *$ & $0.031^{*}$ \\
\hline & $(0.033)$ & $(0.017)$ \\
\hline Observations & 1446 & 1446 \\
\hline R-squared & 0.031 & 0.063 \\
\hline Province Fixed Effect & Yes & Yes \\
\hline Year Fixed Effect & Yes & Yes \\
\hline \multicolumn{3}{|c|}{$\begin{array}{l}\text { Robust standard errors are clustered at the subdistrict level. Estimation is at } \\
\text { the IFLS community level. Estimation data are based on matches between } \\
\text { IFLS communities with PODES. Disease epidemic data are from PODES 2000, } \\
\text { PODES 2003, PODES 2006, PODES 2008, and PODES 2011. Estimations } \\
\text { control for average temperature in the given year. }\end{array}$} \\
\hline
\end{tabular}

